\title{
Foveal atrophy and macular hole formation following intravitreal ranibizumab with/without photodynamic therapy for choroidal neovascularization secondary to age-related macular degeneration
}

\author{
This article was published in the following Dove Press journal: \\ Clinical Ophthalmology \\ 10 February 2011 \\ Number of times this article has been viewed
}

Pukhraj Rishi

Nachiappan Kasinathan

Chinmaya Sahu

Shri Bhagwan Mahavir Vitreoretinal Services, Sankara Nethralaya, I8 College Road, Chennai-600006. Tamil Nadu, India
Correspondence: Pukhraj Rishi Shri Bhagwan Mahavir Vitreoretinal Services, Sankara Nethralaya,

18 College Road, Chennai-600006,

Tamil Nadu, India

Tel +914428271616

$\mathrm{Fax}+914428254180$

Email docrishi@yahoo.co.in
Background: To report the occurrence of foveal atrophy and macular hole formation following intravitreal ranibizumab with or without photodynamic therapy for choroidal neovascularization caused by age-related macular degeneration.

Methods: This was a retrospective, interventional case series, in which 78 eyes of 76 patients were treated for wet age-related macular degeneration between February 2007 and August 2007. Of these, three eyes developed foveal atrophy following treatment. Two eyes underwent combination photodynamic therapy and intravitreal ranibizumab, and one eye underwent intravitreal ranibizumab alone. One of the two eyes that underwent combination therapy progressed to develop a macular hole.

Results: On the first follow-up visit, all three eyes showed thinning of the fovea on optical coherence tomography. Subsequently, treatment was continued with repeat intravitreal ranibizumab injections. At the last follow-up, although choroidal neovascularization regressed in all eyes, extensive foveal atrophy developed in two eyes with macular hole formation in one eye.

Conclusion: The possibility of foveal atrophy and macular hole formation must be borne in mind before initiating ranibizumab in combination with or without photodynamic therapy. However, larger studies with longer follow-up are required to understand such adverse effects better.

Keywords: age-related macular degeneration, choroidal neovascularization, macular hole, foveal atrophy, photodynamic therapy, ranibizumab

\section{Introduction}

Macular hole formation has been reported following photodynamic therapy, ${ }^{1}$ intravitreal ranibizumab, ${ }^{2}$ and intravitreal bevacizumab. ${ }^{3}$ To determine such adverse events in our patients, we reviewed cases of treated wet age-related macular degeneration between February 2007 and August 2007. Twenty-five eyes underwent photodynamic therapy (Novartis, Basel, Switzerland), 53 eyes underwent intravitreal ranibizumab (Genentech, San Francisco, CA), and four of these eyes underwent a combination of the two treatments. Three cases developed foveal atrophy following treatment, and one of these progressed to develop macular hole. Two eyes underwent combination therapy, and one underwent intravitreal ranibizumab monotherapy. Macular hole formation following combination photodynamic therapy and intravitreal ranibizumab has not been reported previously. 


\section{Case I}

A 74-year-old gentleman presented with decreased vision bilaterally. Best corrected visual acuity (BCVA) was 6/18 in the right eye and FC $1 \mathrm{~m}$ in the left. Biomicroscopic examination of the fundus revealed choroidal neovascularization in the right eye (Figure 1, upper left) and a disciform scar in the left. Clinical findings were confirmed on fundus fluorescein angiogram (450 Plus IR, Carl Zeiss Meditec AG, Germany, Figure 1, upper right and lower right) and optical coherence tomography (Stratus Model 3000 Carl Zeiss Meditec AG, Germany, Figure 1, lower left). The patient underwent combination photodynamic therapy $\left(50 \mathrm{~J} / \mathrm{cm}^{2}\right)$ with intravitreal ranibizumab $(0.5 \mathrm{mg} / 0.05 \mathrm{~mL})$ in the right eye. He came back two months later, at which time vision had improved to $6 / 12 \mathrm{P}$. However, optical coherence tomography revealed persisting subretinal fluid (Figure 2, left column, middle), and intravitreal ranibizumab was repeated. He came back for a follow-up six months later (Figure 2, left column, bottom), by which time vision had dropped to 6/36. The fundus revealed regressed choroidal neovascularization with foveal atrophy, confirmed on optical coherence tomography. Thereafter, the patient was followed up regularly at three-monthly intervals. Twenty-five months after the last intravitreal injection, the fundus remained stable and vision was maintained.

\section{Case 2}

A 68 year-old gentleman presented with failure of visual improvement in the right eye following cataract surgery.

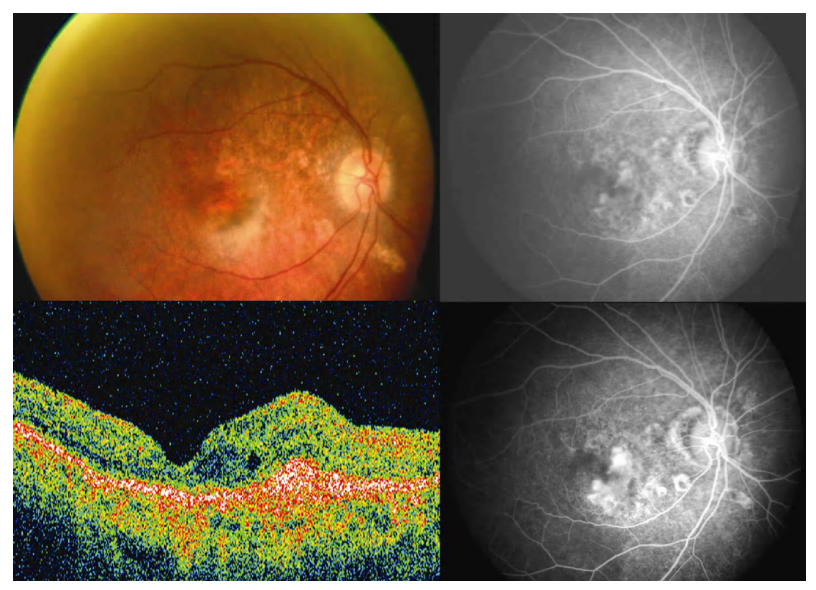

Figure I Case I: Color fundus photograph of the right eye (upper left) shows a grayish-brown subfoveal lesion suggestive of choroidal neovascular membrane. Early hyperfluoresence with intense late staining on fundus fluorescein angiography confirms the presence of predominantly classic choroidal neovascularization (upper right and lower right). Optical coherence tomography scan reveals the presence of a high reflective, spindle-shaped lesion abutting the fovea with increased overlying retinal thickness and intraretinal cystoid spaces (lower left).
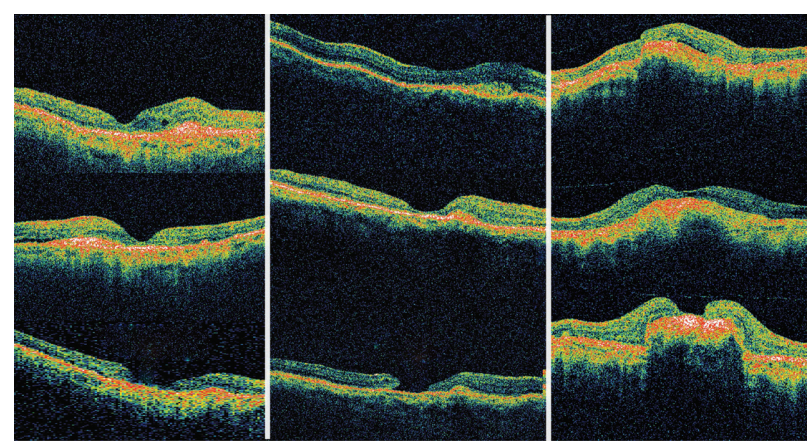

Figure 2 Sequential comparison of optical coherence tomography scans over time for the three study eyes. Column I denotes Case I: At presentation (left, top), two months after initial treatment (left, middle), and at last follow-up (left, bottom). Column 2 denotes Case 2: At presentation (central, top), four weeks after initial treatment (central, middle), and at last follow-up (central, bottom). Column 3 denotes Case 3: At presentation (right, top), four weeks after initial treatment (right, middle), and at last follow-up (right, bottom). Cases I and 3 reveal progressive retinal thinning at the macula, while Case 2 reveals retinal thinning with evolution of full- thickness macular hole.

BCVA was $6 / 60$ in the right eye and $6 / 9$ in the left. Biomicroscopic examination of the right fundus revealed choroidal neovascularization (Figure 3, upper left). Clinical findings were confirmed on fundus fluorescein angiography (Figure 3, upper right and lower right) and optical coherence tomography (Figure 3, lower left). The patient underwent photodynamic therapy $\left(50 \mathrm{~J} / \mathrm{cm}^{2}\right)$ with intravitreal ranibizumab $0.5 \mathrm{mg}$. One month later, vision was $6 / 60$, and the fundus showed choroidal neovascularization with foveal thinning, which was confirmed on optical

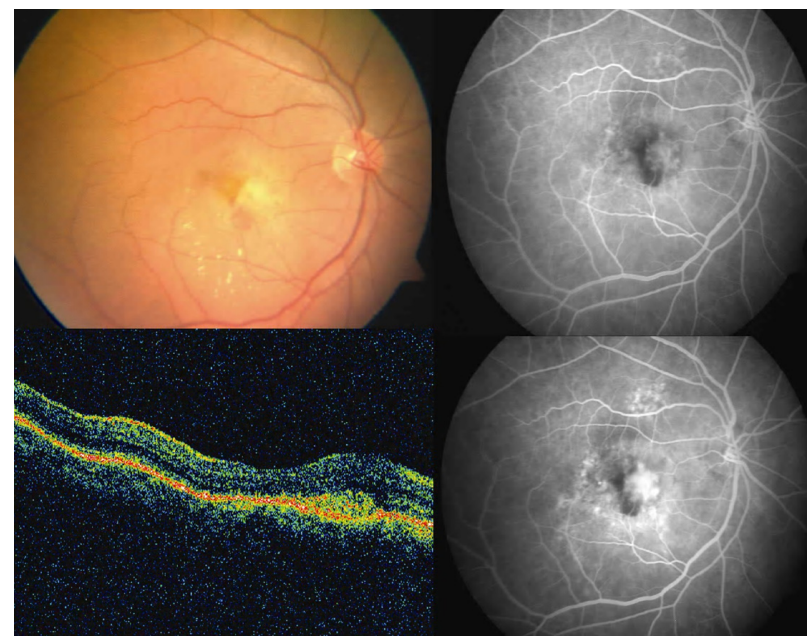

Figure 3 Case 2: Color fundus photograph of the right eye (upper left) shows a yellowish-gray subfoveal lesion suggestive of choroidal neovascularization with specks of fresh subretinal hemorrhage. Early hyperfluoresence with intense late staining on fundus fluorescein angiography confirms the presence of predominantly classic choroidal neovascularization (upper right and lower right); blocked fluorescence corresponds to subretinal hemorrhage. Optical coherence tomography scan reveals the presence of a high reflective, spindle-shaped lesion in the subretinal area abutting the fovea with increased overlying retinal thickness (lower left). 
coherence tomography (Figure 2, central column, middle). Monthly intravitreal ranibizumab injections were repeated twice. One month later, choroidal neovascularization had regressed and vision was improved to $6 / 36$. The patient was followed up on a monthly basis. Three months later, vision was maintained but optical coherence tomography revealed a full-thickness macular hole (Figure 2, central column, below).

\section{Case 3}

A 69-year-old gentleman presented with bilaterally decreased vision over the previous few months. BCVA in the right eye was $6 / 9$ and $6 / 60$ in the left eye. Biomicroscopic examination of the fundus revealed choroidal neovascularization in both eyes (left eye, Figure 4, upper left) which was confirmed on fundus fluorescein angiography (Figure 4, upper right and lower right). Optical coherence tomography showed subretinal fluid and cystoid macular edema (Figure 4, lower left) in the left eye. The patient underwent combination photodynamic therapy $\left(50 \mathrm{~J} / \mathrm{cm}^{2}\right)$ and intravitreal ranibizumab $0.5 \mathrm{mg}$ in the right eye and received intravitreal ranibizumab $0.5 \mathrm{mg}$ in the left eye. One month later, intravitreal ranibizumab was repeated in both eyes. The patient was followed up on a monthly basis. Three months later, vision in the right eye improved to 6/9 and worsened to FC $2 \mathrm{~m}$ in the left. Optical coherence tomography revealed foveal atrophy in the left eye (Figure 2, right column, lower).

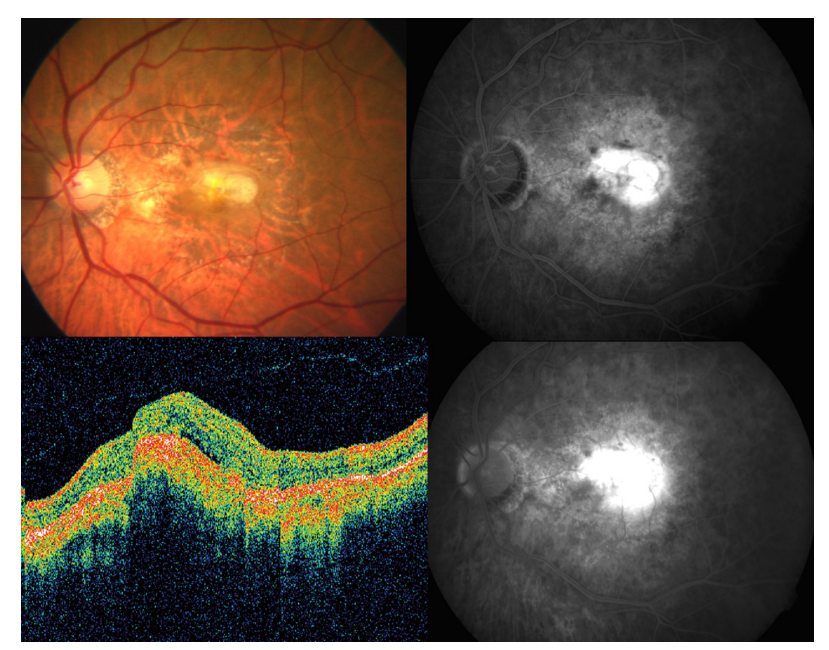

Figure 4 Case 3: Color fundus photograph of the left eye (upper left) shows a partially regressed choroidal neovascularization. Early hyperfluoresence with intense late staining on fundus fluorescein angiography confirms the presence of choroidal neovascularization (upper right and lower right). Optical coherence tomography scan reveals the presence of subfoveal fluid and cystoid macular edema associated with the choroidal neovascularization (lower left) in the left eye.

\section{Discussion}

Various theories have been postulated to account for macular hole formation. Gass ${ }^{4}$ hypothesized that contraction of the prefoveal vitreous cortex caused focal tangential traction, leading to formation of idiopathic macular holes. Gaudric et $\mathrm{al}^{5}$ in an optical coherence tomography study concluded that vitreous traction may actually be oblique. Therefore, tangential and anterior-posterior transvitreal traction has been implicated in the development of idiopathic macular holes. Chung et $\mathrm{al}^{6}$ hypothesized that intravitreal injection can induce vitreous incarceration, causing vitreoretinal traction leading to the development of a macular hole. It is also postulated that ranibizumab itself can cause the macular hole by modulating the activity of choroidal neovascularization and inducing contraction of the membrane, leading to exacerbation of tangential traction on the overlying retina. ${ }^{2}$ Macular hole formation has been reported 20 days after photodynamic therapy. ${ }^{1}$ This reported eye had pre-existing posterior vitreous detachment. Macular hole formation following photodynamic therapy was attributed to choroidal swelling leading to dehiscence of the foveal pit, exacerbation of tangential traction by the laser administered over the fovea, or exacerbation of cystoid macular edema with coalescence of cysts, leading to full-thickness macular hole. In a report of macular hole formation following intravitreal triamcinolone acetonide injection for diabetic macular edema, ${ }^{7}$ the authors hypothesized that there was degeneration of the retinal cells, especially Muller cells, after prolonged edema.

In our patients, several possible mechanisms may have induced the development of macular hole, including those discussed above. Hence, to conclude, the possibility of development of foveal atrophy and macular hole must be kept in mind before initiating combination therapy with photodynamic therapy and ranibizumab. However, larger studies with longer follow-up could unravel such adverse effects better.

\section{Disclosure}

The authors report no conflicts of interest in this work.

\section{References}

1. Mansour AM, Husseini ZM, Schakal AR. Macular hole following photodynamic therapy. Ophthalmic Surg Lasers. 2002;33:511-513.

2. Querques G, Souied EH, Soubrane G. Macular hole following intravitreal ranibizumab for choroidal neovascular membrane caused by age related macular degeneration. Acta Ophthalmol. 2009;87(2):235-237.

3. Georgalas I, Rouvas A, Kotsolis A, Karagiannis D, Ladas I. Full thickness macular hole formation in a patient with cystoid macular edema caused by CRVO treated with intravitreal bevacizicumab. Ophthalmic Surg Lasers Imaging. March 9, 2010. [Epub ahead of print]. 
4. Gass JD. Idiopathic senile macular holes: Its early stages and pathogenesis. Retina. 2003;23(6 Suppl):629-639.

5. Gaudric A, Haouchine B, Massin P, et al. Macular hole formation: New data provided by optical coherence tomography. Arch Ophthalmol. 1999; 117(6):744-751.

6. Chung EJ, Koh HJ. Retinal detachment with macular hole following combined photodynamic therapy and intravitreal bevacizumab injection. Korean J Ophthalmol. 2007;21(3):185-187.
7. Lecleire-Collet A, Offret O, Gaucher D, et al. Full-thickness macular hole in a patient with diabetic cystoid macular oedema treated by intravitreal triamcinolone injections. Acta Ophthalmol Scand. 2007;85(7): 795-798.

\section{Publish your work in this journal}

Clinical Ophthalmology is an international, peer-reviewed journal covering all subspecialties within ophthalmology. Key topics include: Optometry; Visual science; Pharmacology and drug therapy in eye diseases; Basic Sciences; Primary and Secondary eye care; Patient Safety and Quality of Care Improvements. This journal is indexed on PubMed

Submit your manuscript here: http://www.dovepress.com/clinical-ophthalmology-journal
Central and CAS, and is the official journal of The Society of Clinical Ophthalmology (SCO). The manuscript management system is completely online and includes a very quick and fair peer-review system, which is all easy to use. Visit http://www.dovepress.com/testimonials. php to read real quotes from published authors. 